\section{A Cultivar by Any Other Name: Genetic Variability in Heirloom Bell Pepper 'California Wonder'}

\author{
Eric J. Votava and Paul W. Bosland ${ }^{1}$ \\ Agronomy and Horticulture Department, New Mexico State University, Las \\ Cruces, NM 88003
}

Additional index words. bell pepper, DNA, genetic diversity, RAPD, Capsicum annuum L. var. annuum

\begin{abstract}
Random amplified polymorphic DNA (RAPD) analysis can provide a means of evaluating and comparing genetic variability within cultivars. The purpose of this study was to evaluate the relative genetic variability between accessions of two open-pollinated bell pepper cultivars: 'California Wonder', an heirloom cultivar, and 'Jupiter', a modern cultivar. RAPD molecular markers were used to assess the genetic variability between accessions of these two cultivars. The high levels of genetic variability found among accessions of 'California Wonder' may preclude its use as a standard cultivar in research.
\end{abstract}

Prior to 1900 , and the rediscovery of Mendel's laws of genetic inheritance, the importance of varietal purity was neither fully appreciated nor fully applied. It is remarkable to note that scientists at the beginning of the 20th century were skeptical of the true level of diversity between pepper cultivars then available; as V.R. Boswell (1937) wrote, "in 1901 American seedsmen listed between 125 and 150 varietal names of peppers in their catalogs. Of this number, only 18 to 20 probably denoted really distinct varieties, the others being merely synonyms or cases of misnaming." Over the last 100 years, cultivar development and purity have been aided by both scientific progress and legislative protection. Still, there are many reasons a cultivar may deteriorate, or "run out" to use grower's terms. Outcrossing, seed mixes, poor record keeping, and misrepresentation are some reasons why cultivars lose characteristics inherent in the original releases. The development of molecular markers has allowed for comparisons of genetic variability between individuals. Understanding the relative variability and genetic structure of a cultivar using molecular markers is of importance for a number of reasons. First, genetic characterization, or molecular fingerprinting, of a cultivar may be important in terms of establishing proprietary ownership (Lefebvre et al., 2001; Prince et al., 1995), or genetic characterization may clarify cultivar identity when synonymous names occur for the same cultivar (Barranco et al., 2000). Second, a greater understanding of a cultivar's genetic structure may provide researchers and plant breeders with information that could be important to future cultivar development. An example is the use of markerassisted selection in which a marker-identified

Received for publication 26 Dec. 2001. Accepted for publication 25 Mar. 2002. A contribution of the New Mexico Agricultural Experiment Station, New Mexico State Univ., Las Cruces, NM 88003.

${ }^{1}$ To whom reprint requests should be addressed. E-mail:pbosland@nmsu.edu. gene or genes of interest are followed as they are introgressed into the genetic background of a recurrent parent (Hospital, 2001). Finally, molecular markers can be useful for germplasm characterization, and evaluation of collections (Skroch et al., 1998).

The purpose of this study was to use random amplified polymorphic DNA (RAPD) molecular markers to evaluate the relative genetic variability between accessions of two open-pollinated bell pepper cultivars: 'California Wonder', an heirloom cultivar, and 'Jupiter', a modern cultivar.

'California Wonder' is one of the earliest bell pepper cultivars described. In 1937, the Yearbook of Agriculture described 'California Wonder' as a selection by a California grower, originating in $\approx 1928$, and further described as follows:

"'California Wonder' is considered the most important improvement in many years on account of its large size, attractive form, uniformity, and very thick, firm flesh. It is rather late, however, and not well adapted to the northern third of the United States" (Boswell, 1937).

'California Wonder' is still commercially available. Additionally, it is recognized by the Committee for Capsicum Gene Nomenclature as a cultivar that stands as a normal or wildtype genotype for C. annuum (Daskalov and Poulos, 1994), and is commonly used as a standard cultivar in research (Fery and Dukes, 1996; Marrush et al., 1998; Roberts, 1994; Thies et al., 1998).

In 1985, Northrup King Co. (now Syngenta) received U.S. Plant Variety Protection for the cultivar Jupiter, which, like 'California Wonder', is an open-pollinated bell pepper. Because of its recent introduction and its proprietary nature, strict control over its seed production has been practiced, which is not the case for 'California Wonder'.

Comparisons of RAPD variability in 'California Wonder' compared to 'Jupiter' provided a means of characterizing the genetic nature of these two cultivars. Information about the ge- netic nature of these two cultivars can then be used concerning their future use in research.

\section{Materials and Methods}

Plant material. Seeds of 'California Wonder' were obtained from 10 sources (Table 1). Each source was considered a separate accession. Seeds of 'Jupiter' were obtained from Dr. Steve Czaplewski of Syngenta Seeds and from commercial sources. 'Jupiter' seeds from Dr. Czaplewski were produced in different years and in different locations under the control of the breeding and production personnel of Syngenta. Two other bell pepper cultivars were added as cultivar out-groups to evaluate whether RAPD analysis could delineate differences between additional cultivars. These cultivars were 'Belle Star Hybrid' and 'Enterprise' (Table 1).

Seeds were planted in a soilless planting medium (Peatlite; Scotts-Sierra Horticultural Products Co., Marysville, Ohio) in 12-celled bedding plant containers measuring $3.9 \times 2.7$ $\times 5.5 \mathrm{~cm}$ (Hummert International, Earth City, Mo.). Seed trays were maintained in a climatecontrolled greenhouse at the Fabian Garcia Science Center, Las Cruces, N.M. Trays were watered twice daily. After germination, seedlings were fertilized with $\approx 1.5 \mathrm{~g}$ of slowrelease fertilizer (Osmocote, $14 \mathrm{~N}-4.2 \mathrm{P}$ $11.6 \mathrm{~K})$. When plants had 8 to 10 true leaves, DNA samples of leaf tissue were taken. Two plants were randomly selected from each accession.

DNA extraction. Leaf samples were obtained by clipping five leaf disks from each plant using the cap of a sterile $1.5-\mathrm{mL}$ microcentrifuge tube. Samples were kept in liquid nitrogen until DNA was extracted. DNA was extracted using a CTAB extraction technique (Richter et al., 1991) modified to fit a 1.5-mL eppendorf tube. DNA samples were quantified using a fluorometer and brought to a final working concentration of $10 \mathrm{ng} \cdot \mathrm{mL}^{-1}$ in TE buffer.

$P C R$ reaction. $\mathrm{PCR}$ reactions were carried out in a GeneAmp 9600 thermal cycler system (Perkin Elmer). The PCR protocol of Gallego and Martinez (1997) was used. The PCR reagent mixture protocol was provided by Dr. Molly Jahn (Cornell Univ., Ithaca, N.Y.). An initial master mix of PCR reagents was made. This mixture contained $121 \mu \mathrm{L}$ dd $_{2} \mathrm{O}, 220$ $\mu \mathrm{L}$ of 10X Stoffel Buffer, $308 \mu \mathrm{L} 25 \mathrm{~mm}$ $\mathrm{MgCl}_{2}, 88 \mu \mathrm{L}$ of dNTP (2.5 mm each), $22 \mu \mathrm{L}$ of Stoffel fragment (10 units $/ \mu \mathrm{L})$, and $106 \mu \mathrm{L}$ $2.5 \mathrm{~mm}$ primer to bring the final volume to 865 $\mu \mathrm{L}$. To each of 96 reaction tubes, $8 \mu \mathrm{L}$ of this mixture was added to $10 \mu \mathrm{L} \mathrm{ddH_{2 }} \mathrm{O}$. DNA (20 ng), derived from individual plant samples, was added to individual tubes. A total of 28 primers from Operon Technologies (Alameda, Calif.) were used. These primers were OPA02, OPA-04, OPA-07, OPA-10, OPA-11, OPA-15 OPA-18, OPC-01, OPC-02, OPF-06, OPG-06, OPG-16, OPG-19, OPI-01, OPAA11, OPAB-07,OPAB-09, OPAB-10, OPAB14, OPAB-19, OPAC-10, OPAD-09, OPAE02, OPAE-11, OPAF-11, OPAJ-11, OPAN$10, \mathrm{OPV}-03$. These primers had been shown to 
Table 1. Twenty-three bell pepper accessions used for RAPD analysis. Two plants per accession were sampled as denoted by consecutive numbers in each row of the accession column.

\begin{tabular}{|c|c|c|}
\hline Accession & Cultivar name & Source \\
\hline BSH 39, 40 & Belle Star Hybrid & Ferry Morse \\
\hline E 41,42 & Enterprise & Asgrow \\
\hline CW 47, 48 & California Wonder & NK Lawn and Garden \\
\hline CW 49, 50 & California Wonder & Burpee Seed Co. \\
\hline CW 51, 52 & California Wonder & American Seed \\
\hline CW 53, 54 & California Wonder & Lake Valley Seed \\
\hline CW 55, 56 & California Wonder & Enchanted Seed \\
\hline CW 57, 58 & California Wonder & The Pepper Gal \\
\hline CW 59, 60 & California Wonder & Stokes Seed \\
\hline CW 61, 62 & California Wonder & Dr. A. Palloix, INRA, France \\
\hline CW 63, 64 & California Wonder & Dr. A. Palloix (Received from PetoSeed) \\
\hline CW 65, 66 & California Wonder & Willhite Seed Inc. \\
\hline J 67,68 & Jupiter & The Pepper Gal \\
\hline $\mathrm{J} 69,70$ & Jupiter & NK Lawn and Garden \\
\hline $\mathrm{J} 71,72$ & Jupiter & Stokes Seeds \\
\hline $\mathrm{J} 73,74$ & Jupiter & Better Homes and Gardens \\
\hline J 75,76 & Jupiter & Tomato Growers \\
\hline $\mathrm{J} 77,78$ & Jupiter & 41884-JS710 (1994) \\
\hline J 79,80 & Jupiter & 41884-A7019(1982) \\
\hline J 81,82 & Jupiter & 41884-ES120 (1991) \\
\hline J 83,84 & Jupiter & 41884-LS830 \\
\hline J 85,86 & Jupiter & 41884-RS030 \\
\hline $\mathrm{J} 87,88$ & Jupiter & 41884-MF550 \\
\hline
\end{tabular}

produce polymorphic bands in Capsicum (personal observation/unpublished data). Only polymorphic bands were analyzed and only if they produced scorable and repeatable polymorphic gel patterns. Amplification products were separated on $2 \%$ wide range 3:1 agarose gels (Sigma Chemical Co., St. Louis) run in TBE buffer. Before loading gels, $4 \mu \mathrm{L}$ of gelloading solution (Sigma Chemical Co.) was added to amplification products. A 100-bp DNA ladder (CibcoBRL, Gaithersburg, Md.) was included in each gel as a reference standard. Gels ran for $5 \mathrm{~h}$ at 130 volts. Gels were stained in $300 \mathrm{~mL}$ ethidium bromide solution ( 10 mL ethidium bromide per $100 \mathrm{~mL} \mathrm{H}_{2} \mathrm{O}$ ) on a mechanical rocker for $30 \mathrm{~min}$, then washed in $300 \mathrm{~mL} \mathrm{ddH}_{2} \mathrm{O}$ for $30 \mathrm{~min}$. Gels were placed on a UV transilluminator and photographed using Technical Pan black and white film. Gels were scored visually from photographic negatives. All PCR reactions were repeated and all gels were visually scored by two separate individuals.

Data analysis. Polymorphic RAPD band patterns on agarose gels were visually scored for presence or absence of DNA fragments. If a fragment was present at a specific fragment size, it was assigned a " 1 ." If the fragment was absent at that fragment size, it was scored as a "0." Intensity of a fragment image was not taken into consideration. Pairwise genetic similarity was calculated using Nei and Li's Coefficient (Nei and Li, 1979):

$$
\mathrm{S}_{\mathrm{ij}}=2 \mathrm{~N}_{\mathrm{ij}} /\left(\mathrm{N}_{\mathrm{i}}+\mathrm{N}_{\mathrm{j}}\right) \text {, }
$$

where $\mathrm{N}_{\mathrm{ij}}=$ the number of bands shared by samples $\mathrm{i}$ and $\mathrm{j}, \mathrm{N}_{\mathrm{i}}$ and $\mathrm{N}_{\mathrm{j}}$ are the numbers of fragments in samples $i$ and $j$, respectively.

RAPD data were processed using the software package Numerical Taxonomy and Multivariate Analysis for Personal Computers (NTSYS-pc) V. 2.20 (Rohlf, 1992). Data were analyzed with the Similarity for Qualitative (SIMQUAL ) data function using the Dice similarity formula, which is the same as Nei and Li's Coefficient (Dudley, 1994). A dendogram was constructed using Unweighted Pair-Group Method with Arithmetic Averages (UPGMA) using the Sequential Agglomerative, Hierarchical and Nested (SAHN) clustering function.

\section{Results}

A total of 28 primers produced 357 monomorphic and polymorphic RAPD bands. No differences were observed when reactions were repeated or scored separately. Out of 357 bands, only eight were polymorphic and were derived from four primers. Primers OPA-02, OPA-04, OPA-18, and OPAC-10 generated the eight polymorphic bands. Data from the polymorphic bands were used to generate a table of genetic similarities and a dendogram that depicts the relative genetic similarity values among the bell pepper accessions (Fig. 1). At a genetic similarity value of 0.86 , the dendogram delineated six unique clusters: A through F. (Fig. 1). 'Jupiter', 'Belle Star Hybrid', and 'Enterprise' were all differentiated from one another at a genetic similarity value of $\approx 0.75$. At the same genetic similarity value of 0.75 , 'California Wonder' accessions segregated into five clusters.

RAPD analysis revealed greater genetic variability between accessions of the cultivar California Wonder compared to that of the cultivar Jupiter. In fact, no differences were observed at all among any of the accessions of 'Jupiter'. 'Jupiter' was associated with cluster D (Fig. 1). The 10 'California Wonder' accessions were distinguished among five different clusters (A, B, D, E, and F) (Fig. 1). Six 'California Wonder' samples, representing three accessions, clustered with 'Jupiter' in cluster D. Six other samples, again representing three accessions, clustered with 'Belle Star Hybrid' in cluster A. Finally, eight samples, representing four accessions of 'California Wonder', separated into three different clusters $(\mathrm{B}, \mathrm{E}$, and $\mathrm{F})$ at a genetic similarity value of 0.86 , with one accession (CW49, CW50) exhibiting genetic variability between the two plants sampled from that accession. The CW49 and CW50 samples were also genetically most dissimilar relative to all other bell pepper samples.

\section{Discussion}

Paran et al. (1998) found that 21 RAPD primers could not distinguish several largefruited nonpungent cultivars, including 'Jupiter', from one another. Bell peppers have been shown to contain less genetic variability relative to other Capsicum annuum pod-types or accessions (Lefebvre et al., 1993; Paran et al., 1998). The relatively narrow genetic variability of this pod-type was substantiated in this study by the observation that only four primers generated polymorphic bands out of 28 primers that are capable of revealing polymorphisms in Capsicum (personal observation/ unpublished data). However, the protocols described in this study proved useful in differentiating genetically similar phenotypes. The polymorphic bands were adequate in terms of testing the hypothesis. RAPD analysis supported the hypothesis that 'California Wonder' contains greater variability at the genetic level compared to 'Jupiter'. Furthermore, because RAPD molecular markers are assumed to randomly sample the genome, an assumption is made that additional sampling of primers would not greatly change the overall pattern of relative genetic variability observed between accessions of the two cultivars; that is, 'California Wonder' would still be genetically more variable than 'Jupiter'.

Barranco et al. (2000) used molecular markers to show that two cultivars of olive were, in all likelihood, the same cultivar. Conversely, the results of this research demonstrate that the cultivar California Wonder exists in name only. The genetic variability in 'California Wonder' exists, for the most part, between seed sources of this "cultivar" rather than within seed sources. The molecular genetic diversity in 'California Wonder' accessions has several implications. Different sources of 'California Wonder' can be genetically distinguished from one another at the molecular level and can be separated via RAPD analysis. The accessions of 'California Wonder' available today may represent selections from an originally genetically diverse germplasm pool, resulting in different accessions becoming fixed for different RAPD alleles. This scenario is metaphorically consistent with a founder's effect in which a small sample of an originally genetically diversified population becomes the source of a new population, but contains only a small sample of the genetic variability found in the original population. Additionally, modern sources of 'California Wonder' may not be related to an original source at all and may have arisen from a variety of causes, including seed mixing, mislabeling, or misrepresentation. Genetically variable accessions of 'California Wonder' could also arise from crosspollination with other Capsicum cultivars. Cross-pollination can occur in Capsicum from $2 \%$ to $90 \%$ (Pickersgill, 1997) unless steps are 


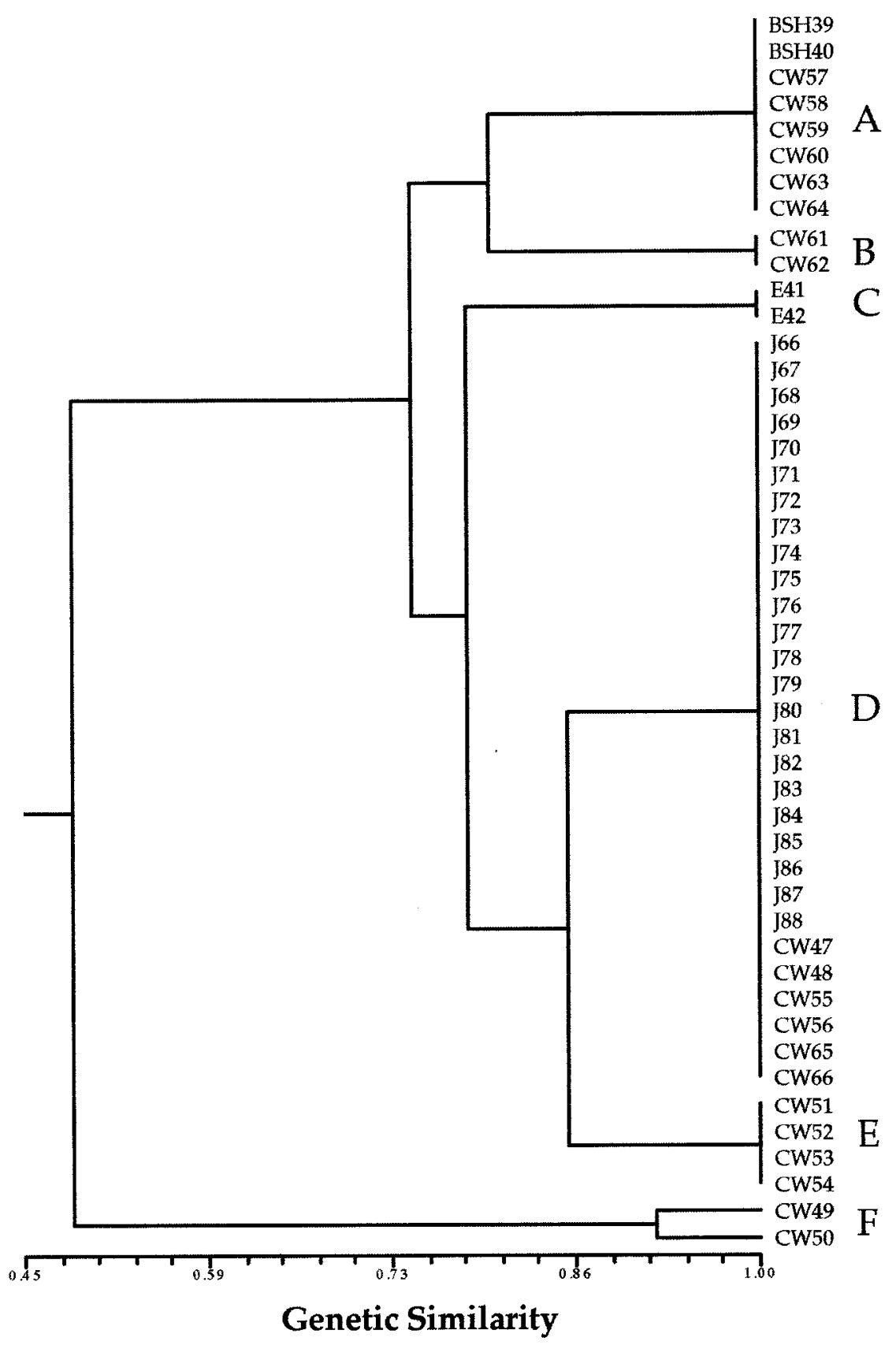

Fig. 1. Dendogram depicting relative genetic similarities based on Nei and Li's similarity index of 46 bell pepper samples representing 23 accessions from four different cultivars of bell pepper. Labels refer to labels in Table 1.

taken to ensure seed purity (Bosland, 1993).

The existence of polymorphic RAPD loci between accessions of the cultivar California Wonder casts into doubt the reliability of using this "cultivar" as a standard for allelic nomenclature or other genetic studies. Using a more homogenous line or, more preferably, an isogenic line within $C$. annuum that could be made available via a few germplasm repositories would allow for a more standardized "wild type" representative and would aid researchers worldwide in studies of Capsicum genetics.

Conversely, the conservation of various accessions of 'California Wonder' and other heirloom cultivars may be a means of preserving Capsicum germplasm genetic diversity. A recent query of the Germplasm Resources Information Network (GRIN) showed that four out of five 'California Wonder' accessions in the National Plant Germplasm System(NPGS) were labeled as duplicates of the cultivar and were made inactive. Some of those accessions came from different sources and therefore could have been genetically variable relative to one another.

'California Wonder' should not be included as a standard control in other Capsicum research as well. The concept of a standard control entails that the "control" can be used in separate labs and in separate experiments and act as a consistent and repeatable benchmark. The dependability of a sample to act as a standard control is cast into doubt if it is shown to contain a high degree of variability or if even a high degree of variability is suspected. The process of plant variety protection (PVP) for new cultivars, for example, would be rendered unreliable if comparisons are made to a cultivar containing too much variability, especially if that variability exists between sources. Again, a more genetically homogenous cultivar would be a better choice as a standard control. The implications from the results of this study could likewise be conveyed to the use of any older or heirloom cultivar of any crop that is being considered as a control.

RAPD analysis has proven useful in clarifying the relative genetic variability between and within accessions of the cultivars California Wonder and Jupiter. Further use of 'California Wonder' in scientific research as a reference standard is questioned given the added information concerning the genetic structures of these two cultivars.

\section{Literature Cited}

Barranco, D., I. Trujillo, and P. Rallo. 2000. Are 'Oblonga' and 'Frantoio' olives the same cultivar? HortScience 35:1323-1325.

Bosland, P.W. 1993. An effective plant field-cage to increase the production of genetically pure chile (Capsicum spp.) seed. HortScience 289:1053.

Boswell, V.R. 1937. Improvement and genetics of tomatoes, peppers, and eggplant. In: Yearbook of agriculture. Washington D.C., U.S. Dept. Agr. p. 176-206.

Daskalov, S. and J.M. Poulos. 1994. Updated Capsicum gene list. Capsicum and Eggplant Nswl. 13:15-26.

Dudley, J.W. 1994. Comparison of genetic distance estimators using molecular marker data. In: Proc. Symp. Analysis of Molecular Marker Data. ASHS/CSSA. p. 3-7.

Fery, R.L. and P.D. Dukes. 1996. The inheritance of resistance to the southern root-knot nematode in 'Carolina Hot' cayenne pepper. J. Amer. Soc. Hort. Sci. 121:1024-1027.

Gallego, F.J. and I. Martinez. 1997. Method to improve reliability of random amplified polymorphic DNA markers. Biotechniques 23:663-664.

Hospital, F. 2001. Size of donor chromosome segments around introgressed loci and reduction of linkage drag in marker-assisted backcross programs. Genetics 158:1363-1379.

Lefebvre, V., A. Palloix, and M. Rives. 1993. Nuclear RFLP between pepper cultivars (Capsicum annuum L.). Euphytica 71:189-199.

Lefebvre, V., B. Goffinet, J.C. Chauvet, B. Caromel, P. Signoret, R. Brand, and A. Palloix. 2001. Evaluation of genetic distances between pepper inbred lines for cultivar protection purposes: Comparison of AFLP, RAPD and phenotypic data. Theor. Appl. Genet. 102:741-750.

Marrush, M., M. Yamaguchi, and M.E. Saltveit, 1998. Effect of potassium nutrition during bell pepper development on vivipary and endogenous levels of abscisic acid (ABA). J. Amer. Soc. Hort. Sci. 123:925-930.

Nei, M. and W.H. Li. 1979. Mathematical model for studying genetic variation in terms of restriction endonucleases. Proc. Natl. Acad. Sci. 76:5269-5273.

Paran, I., E. Aftergoot, and C. Shifriss. 1998. Variation in Capsicum annuum revealed by RAPD and AFLP markers. Euphytica 99:167-173.

Pickersgill, B. 1997. Genetic resources and breeding of Capsicum spp. Euphytica 96:129-133.

Prince, J.P., V.K. Lackney, C. Angeles, J.R. Blauth, and M. Kyle. 1995. A survey of DNA polymorphism within the genus Capsicum and the fingerprinting of pepper cultivars. Genome 38:224-231.

Richter, H.E., N.N. Sandal, K.A. Marker, C. SenguptaGopalan. 1991. Characterization and genomic organization of a highly expressed late nodulin gene subfamily in soyabean. Mol. Gen. Genet. 229:445-452.

Roberts, B.W. 1994. Canopy shade and soil mulch affect yield and solar injury of bell pepper. HortScience 29:258-260

Rohlf, F. J. 1992. NTSYS-pc numerical taxonomy and multivariate analysis system. Exeter Software, Setauket, N.Y.

Skroch, P.W., J. Nienhuis, S. Beebe, J. Tohme, and F. Pedraza. 1998. Comparison of Mexican common bean (Phaseolus vulgaris L.) core and reserve germplasm collections. Crop Sci. 38:488- 496

Thies, J.A., J.D. Mueller, and R.L. Fery. 1998. Use of a resistant pepper as a rotational crop to manage southern root-knot nematode. HortScience 33:716-718. 